\title{
Effective Performance Management System for Enhancing Growth At Accra Technical University
}

\author{
Dolores Mensah Hervie \\ Department of Secretaryship and Management Studies, \\ Accra Technical University \\ P. O. Box GP 561, Accra-Ghana
}

\begin{abstract}
Performance management supports and offers a structure for employees to develop the skills they need to achieve organisation's strategic goals. The key features of PMS involve setting objectives, monitoring, motivation, giving timely feedback and measurable performance. There are regular day-to-day meetings as well as periodic feedback meetings with subordinates. An unbiased annual evaluation of performance based on specific assessable targets set at the beginning of the corporate year is carried out. During these end-of-year appraisal face-to-face meetings, achievements and nonachievements of targets are discussed objectively. Necessary steps are then taken to either recognize or improve performance, enhance career development, promote, reward and compensate as deemed fit. The objective of this study is to propose the introduction of Performance Management System in Accra Technical University that would enhance performance and effective growth. A semi structured questionnaire was used and interviews were conducted to gather information from a cross-section of staff in the institution. In all, about 30 questionnaires were distributed and retrieved from both senior and administrative junior staff. PMS manual was designed based on information gathered. The manual spells out the step-by-step procedure or guideline for a successful implementation of PMS. The study concludes and recommends among other things that efforts should be made by the Institution to ensure that staff are given the requisite training in the area of target setting and implementation, recognition of employees' effort and enhance career development which would go a long way to achieve institutional strategic goals and competitive advantage for Accra Technical University.

Key words: Performance, Management, System, Target-setting, Recognition, Reward, Appraisal
\end{abstract}

\section{INTRODUCTION}

Performance management system (PMS) is the core of any human resource management process in an institution. Institutions exist to perform to achieve their objective. If employees do not perform, institutions would not survive. If employees perform at their highest level, institutions would be competitive and productivity would increase. Performance management system (PMS) is a tool that allows managers at all levels in an organization and their subordinates to enhance performance. A key feature in the implementation of PMS is goalsetting.

PMS is very important to a complex institution like Accra Technical University (ATU) where apart from having various managerial levels, the employees can be divided into two distinctive groups - academic and administrative staff. Accra Technical University is a tertiary institution for higher educational pursuits. It was a premier polytechnic situated in the heart of the city of Accra. This Polytechnic (now a technical university) is geared towards training of high quality and diverse middle level management personnel, who would easily fit into the Ghanaian industrial environment and form the backbone of Ghana's development. Accra Technical University distinguishes itself primarily in providing continuous tuition, practical training, 
learning and research. The university is run by a Council, Vice Chancellor and Pro Vice Chancellor, Registrar and other academic and administrative management staff (non-teaching and teaching staff). The institution is guided by its established mission, vision, values, and objectives. In addition, there are policies (admission, administration, human resource management etc.) that also guide the running of the institution. Accra Technical University has evolved into one of the best tertiary institutions credited with practical industrial knowledge which has had impact on Ghana's economy. It attracts students from the sub- region and the rest of the world. Currently, the institution has a student population of over fifteen thousand and a staff strength of above 600 .

Hrcouncil.ca defines Performance management as a process by which managers and employees work together to plan, monitor and review an employee's work objectives and overall contribution to the organization.

Performance management system (PMS) provides an opportunity and an environment for involving individual employees in the performance and productivity improvement effort. It is a powerful tool for tapping individual employee creativity, innovation and effectiveness. Unlike performance appraisal, which is an annual performance review, PMS is the continuous process of setting objectives, assessing progress and providing on-going coaching and feedback to ensure that employees are meeting their objectives and career goals (Hrcouncil.ca).

The introduction of PMS in Accra Technical University would therefore support the institution to achieve its strategic goals. It would assist Management, Deans and Heads of Departments (HODs) in setting clear performance objectives for subordinates that are aligned with the strategic goals. It would provide a structure for staff of the Institution particularly, administrative/technical staff to develop their skills. More so, reward and compensation would be attached to performance.

Currently, evaluation of performance is carried out annually for employees due for promotion. The respective Heads of Departments solely appraise their subordinates. The HODs are given appraisal and promotion forms ((with predetermined "universal" requirements) to fill on behalf of the subordinates/colleagues. Subordinates/colleagues are however, not given the opportunity to comment on their assessments. Usually, employees due for upgrading would fill assessment forms. It is worth mentioning that each category of staff (Junior staff, Senior Staff and Senior Members) have their respective appraisal and promotion forms.

These assessments have no bearing on staff performance, training and development, and emoluments. Employees promoted to the next level attract its commensurate salary. Salary increments are automatic (from the government of Ghana). All staff benefit from government annual percentage increment for all government employees. In addition, various positions are paid their commensurate allowances and incentives. This has led to low motivation and morale, as well as liaise faire attitude among some members of staff. As a Human Resource Practitioner, the researcher observed this trend and realized that there is a gap as far as PMS was concerned

Introduction of PMS as a tool for performance measurement and its added advantages in a tertiary institution like Accra Technical University would help boost the morale of employees at every level to bring forth their best. PMS would also allow management of the institution to precede training and development with learning needs assessment and reward/recognition would be based on performance. The purpose of this study is to examine the appraisal system 
deployed at ATU, recommend a PMS system that may be applicable to the institution and design PMS manual that can be used to guide the implementation of the system in ATU.

\section{LITERATURE REVIEW}

Most organizations are replacing performance appraisal with PMS. Appraisal forms an integral part of PMS but it happens at the tail end of the institutional year.

PMS brings together many aspects of people management. It is about performance improvement at individual, team, department and organizational levels. It is also about staff development as a means to both improve and enhance performance and managing behaviour and attitudes. PMS is designed to overcome the problems of traditional performance appraisal. Various HR experts defined PMS differently. However, the key elements of PMS (target-setting, feedback, face-to-face meeting etc.) as an essential tool for managing employees' performance in an organisation is key. Susan M. Heathfield (2018) defines Performance management as the process of creating a work environment in which people are enabled to perform to the best of their abilities. Performance management is a whole work system that begins when a job is defined as needed and ends when an employee leaves your organization.

According to Heathfield (2018), effective performance management system sets new employees up to succeed, so they can help their organizations succeed. To her, an effective performance management system provides enough guidance, so that employees understand what is expected of them. It also provides enough flexibility and control for employees' creativity and strengths to be nurtured as well as understand what the organization's objectives.

According to McPheat (2010), PMS is a partnership and motivation. It involves many roles one must be a communicator, a leader, a role model and a collaborator. Each individual team member must understand exactly what their expectations are, and the supervisor should help the team reach their goals. To McPheat, when this perspective is shared with employees and they learn to see it that way, PMS becomes a powerful tool that helps teams become more successful.

Mullins (2010) defined PMS as a process which brings together many aspects of people management. It is about performance improvement at individual, team, department and organisational levels. It is also about employees' development as a means to both improve and enhance performance and as a means of managing behaviour and attitude.

Dessler (2011) stated that PMS is the continuous process of identifying, measuring, and developing the performance of individuals and teams and aligning their performance with the organisation's goals. What this means is that results are aligned with established performance standards and the overall goals of the organisation. Necessary adjustments are made to ensure quality and high productivity.

According to Asare-Bediako (2013), the foundation of an effective PMS is the establishment of clear-cut targets, permitting both employees and their supervisors to compare performance against targets periodically.

From the aforementioned definitions, it is clear that overseeing performance and providing feedback is not an isolated event, with the focus on annual performance review. It is a continuous process that takes place throughout the year. The process is a cycle with discussions varying year-to-year based on changing objectives. 
Before embarking on the development of an effective performance management system, one should take a moment to consider whether or not the institution has HR management practices in place to support the performance management process. These include:

- Well-designed jobs and written job descriptions.

- Effective supervision.

- Comprehensive employee orientation and training.

- A positive and supportive work environment.

- Reward and recognition.

- Performance Improvement plan. (source: hrcouncil.ca 20/08/2015)

Based on questionnaires collated from the cross section of staff and interactions with administration and human resource staff, it was clear that Accra Technical University has HR policies on orientation, employee training and development, reward and compensation, staff accommodation, conditions of services, scheme of service etc. Most of the time employees enjoy these facilities based on qualification, years of experience and their contribution towards the wellbeing of the institution. These available policies would aid the implementation of PMS in Accra Technical University.

PMS must be designed with the following features:

- Objective, measurable performance criteria. That is, the standards or targets upon which employees' performance would be measured at the end of the year, must be set and made known to the employees.

- Targets are set based on employees' competencies that is, the technical, personality and managerial competencies of the employees.

- Day-to-day and periodic formal/informal feedback on performance is scheduled with the respective employees before the annual review meeting which provides opportunity to summarize all the feedback provided in the course of the year.

- Objective, unbiased annual assessment of performance would depend on beginning of the year's mutual identification of specific, measurable performance targets or criteria.

- Meetings between supervisors and subordinates allow for objective discussions of achievements and non-achievements of targets, the problems and perspectives of both are also discussed. (Asare-Bediako 2013)

\section{Best Practice Of Performance Management System}

Performance management system is a cycle with three main phases. As soon as the third phase is completed, the first phase begins - it is a never-ending process. (Asare-Bediako 2013)

The first phase is the target-setting stage which is done at the beginning of the corporate year. The target-setting process involves supervisor/manager and subordinate meeting for mutual discussion of targets for the subordinate for the year. The target-setting process follows a topdown approach starting with the Vice Chancellor right down to the last supervisory level. One key factor that guarantees the success of a meeting is adequate preparation especially, on the part of the supervisor. Some of the things the supervisor/manager should consider are:

- The supervisor/manager has set target with his/her immediate supervisor.

- Supervisor/manager sets date, time and place for the target-setting meeting with subordinate.

- The subordinate is encouraged to identify key results areas where performance improvement is needed, set a maximum of about six targets to improve performance, select critical competencies for the achievement of selected targets or overall job performance. 
- The supervisor/manager has the opportunity of selecting two or three targets and competencies that he/she would like to add to those of the appraisee at the meeting.

- During this meeting, the supervisor/manager and appraisee agree on key results areas, targets and competencies.

After the target-setting meeting, the supervisor/manager completes the target-setting form which is signed by both parties. Copies of the form are kept by both and one is put on the subordinate's file.

The second phase is the feedback stage. After target-setting, either the supervisor/manager or subordinate can initiate feedback to keep the other informed about developments affecting the set targets and discuss "additions", "deletions", and "modifications" which need to be made These periodic review meetings may be held quarterly or mid-year and it involves a process of dialogue. Unless serious problems exist, the review meeting need not take a great deal of time.

Day-to-day feedback is provided to feed information for the periodic review meetings and the subsequent end-of-year reviews. This could happen if the appraiser kept notes of "significant events" observed and shared them with the subordinate on a day- to- day basis. Immediate feedback is an important tool geared towards maintaining desirable as well as change unwanted behaviours.

The third and final phase involves end of year review and appraisal of performance. The supervisor/manager meets with the subordinate, reviews the entire year's performance and, on the basis of the review, pronounces his/her "rating" of the subordinate's performance for the entire year.

The success of this end-of-year review meeting depends largely on the supervisor/manager's preparations which are as follow:

- Use a place free from personal and telephone interruptions.

- Schedule a brief meeting to inform the appraisee about the impending review meeting, in terms of date, time and place of meeting.

- On the meeting day, go over targets, competencies, and key day-to-day duties, and write down observations and ratings that the appraiser wants to discuss with the appraisee.

- Record on paper the major points to be discussed at the meeting.

- The supervisor or HR should seek the views of the subordinate's immediate supervisor, observations and ratings recorded for the subordinate. This ensures that the supervisor's judgement is not rejected.

- An agenda must be drawn for the review meeting.

- After the review meeting, the supervisor/manager completes the review form which is signed by both parties and distributed as follows:

○ Employee's copy

○ Employee's file copy

- Supervisor's copy

(Asare-Bediako 2013)

\section{METHODOLOGY}

There are two major categories of staff in Accra Technical University - The academic (senior members and senior staff) and, administrative and technical (senior and junior) staff. Performance management Policy and Procedures Manual is developed for the latter. 
Two types of data were collected for the study -secondary and primary data. In the collection of primary data, a semi-structured questionnaire was used and interviews were conducted to collect information from the respondents. Secondary data was obtained from textbooks, articles on the internet and publications to bring out the essence of the use of PMS.

The Human Resource Management Department (HRMD) should be responsible to ensure that PMS is implemented that is, annual targets are set at each level from the beginning of the institutional year in relation to the required competencies with regular feedback. Performance Appraisal should be conducted at the end of the institutional year (May/June). The Human Resource Management Department should be supported by the Registrar's office.

\section{Objective setting by Administrative Departments:}

As stated earlier, each department is expected to set specific, measurable, achievable, realistic and time-bound (smart) goals. These goals should emanate from the strategic objectives of the institution. The administrative heads of departments that is, HOD Administration, HOD Human Resource, HOD Academic Affairs, planning etc. would have to sit with the Registrar to set their targets. Financial Officer (FO) and Registrar would set their targets in collaboration with the Pro Vice Chancellor.

\section{Setting personal/Individual targets:}

The various HODs would sit with Assistant Registrars and other categories of administrative staff to set their individual targets. FO would sit with the finance team to set their individual objectives. Each objective should fit into and support the overall strategy or goals of the respective department. Objectives are set at the beginning of the institutional year.

Examples of objectives are:

- Increase students' intake from say 1500 to 2000

- Increase internally generated funds from 15 to 20 percent.

- Increase return on investment from 26 to 30 percent

- Staff training and development policy should be implemented by first quarter of 2019.

- Introduce two new BTech programmes by 2018/2019 academic year.

During target setting, there should be mutual agreement between subordinates and their supervisors. Targets are set in line with competencies.

Unaccomplished objectives/ targets may be revised or new objectives could be added during reviews.

Regular feedback between supervisor (s) and subordinate (s) is a key factor in PMS. Each administrative HOD would determine employees under him whom he would set performance target with. This is because there are persons for example, some junior staff who only do routine work and may not require to set individual objectives. However, they would be required to comply with stated performance standards and expectations. Administrative staff, like secretaries, clerks and cleaners.

\section{Performance Standards}

Performance standards are competencies and specific expectations that go with set objectives. Performance standard defines acceptable behaviour. One can never know whether work has been done right if one does not know the expected standard. 
For example, if one is a secretary, one is expected to file documents regularly. That is an "Expectation."

So, filing is dome within a day or two

However, "regularly" stated above might mean different things to different people.

What standard should be used to define regularly?

The correct standard to use is the one that was explicitly given as the Technical University's Standard, or a Professional Standard, which is expected by the Supervisor. Does such a standard exists? If so what is it? Does this standard vary from department to department? It should not, because it is the Technical University's standard or the Standard set by ones profession. (Source: PM Manual of University of West Indies)

Professionally, the secretary is expected to:

- Keep files in organized fashion so that documents are easily located

- Refile documents within one or two days of return

- Checks out files as requested, using proper forms and "file locator tabs"

- Opens new files with appropriate names as required.

Performance Standards and Expectations specify the degree of compliance required. Communication and Clarification of Performance Standards and Expectations is an indispensable requirement of any effective Performance Management System (PMS). Particularly, during performance appraisal or evaluation. Two definitions of "Standard" are:

1. The set of parameters (criteria) used to determine what is acceptable.

2. A guideline to an acceptable performance level.

\section{Performance Indicators}

Performance Indicators (A-S-M-A-R-T-E-R).

Performance Indicators would allow the University to recognise or verify when objectives have been successfully accomplished. They describe in measurable detail the performance levels required by objectives. They make the standards and expectations clearer. Performance Indicators are therefore means of verification. They help to provide the evidence to determine the degree of accomplishment of an objective.

Examples of performance indicators:

\begin{tabular}{|c|c|}
\hline $\begin{array}{l}\text { Performance indicators must describe } \\
\text { change in quality terms }\end{array}$ & $\begin{array}{l}\text { Performance indicators must allow } \\
\text { measurement and or comparison in degree } \\
\text { or degrees of variation. }\end{array}$ \\
\hline - Increased & $\begin{array}{c}\text { - Number of } \\
\text { - Improved }\end{array}$ \\
- Greater & - Percentage of \\
- Stronger & - Frequency of \\
- Higher & - Degree of \\
\hline
\end{tabular}


Examples of objectives with clearer standards:

\begin{tabular}{|l|l|}
\hline \multicolumn{1}{|c|}{ Vague } & \multicolumn{1}{c|}{ Specific } \\
\hline $\begin{array}{l}\text { Our objective is to be a leader among } \\
\text { technical universities in Ghana in terms of } \\
\text { research and development. }\end{array}$ & $\begin{array}{l}\text { Become a leader among technical } \\
\text { universities in Ghana by spending 30\% of } \\
\text { our internally generated fund (IGF) on } \\
\text { research and development 2019. }\end{array}$ \\
\hline Our objective is to maximize IGF. & $\begin{array}{l}\text { Maximise IGF by increasing admissions to } \\
\mathbf{1 0 \%} \text { during 2018/2019 academic year. }\end{array}$ \\
\hline
\end{tabular}

\section{Rating Performance against Preset Objectives and Standards}

Depending on how well actual performance meets or exceeds objectives which have been set with clear performance standards and expectations, the appraiser/supervisor would be able to apply one of the following ratings: 5, 4,2,3,1

\section{5 - FULLY ACHIEVED \\ 4 - SUBSTANTIALLY ACHIEVED \\ 3 - PARTIALLY ACHIEVED \\ 2 - MINIMALLY ACHIEVED \\ 1 - NOT ACHIEVED}

Ask these questions:

- What do I expect my subordinate or team members doing this job to do in terms of, safety, speed, accuracy, neatness, interaction, communication, customer satisfaction, timeliness and so on?

- How do I know when an employee is not meeting standards and expectations?

- For each standard developed, consider at what point one would talk to the employee about improving his or her performance. (Training, Coaching and/or Counseling before Discipline).

- Create a visual image of the employee doing the job the way one expects it to be done. Observe and compare the actual performance against expectation.

- Determine if there are gaps and what should be done to reduce or eliminate them. If standards and/or expectations are being met, or exceeded, express satisfaction.

As noted before, Performance Standards and Expectations are typically expressed in terms of the following:

\begin{tabular}{|c|c|c|}
\hline Quantity & Quality & Manner \\
\hline How much & Degree of precision and/or accuracy & $\begin{array}{l}\text { Specific method or procedure to } \\
\text { follow }\end{array}$ \\
\hline How many & Degree of precision and/or accuracy & Personal requirements \\
\hline How often & $\begin{array}{l}\text { Physical appearance of the product or } \\
\text { service }\end{array}$ & Impact on the customer \\
\hline \multirow[t]{2}{*}{ How soon } & Desired results & Impact on the team \\
\hline & Degree of customer satisfaction & $\begin{array}{l}\text { Impact on the institution (Students, } \\
\text { Faculty, Polytechnic) }\end{array}$ \\
\hline
\end{tabular}

Has the standard been clearly communicated by the supervisor to the subordinate? Has the supervisor checked for understanding? Agreement with the standard is not absolutely necessary but obviously, it helps if there is agreement. (Source: PM Manual of University of West Indies and adapted) 


\section{Twelve suggested steps that would help HODs/Supervisors to write good Performance Objectives}

1. Spend some time to initially think about the institution and the department you belong to. What are the problems your department face? What processes need improvement? What practices need review? What are the developmental needs and requirements of staff and students?

2. Think about what the person for whom the objectives are being prepared is to do.

3. Draft a verb-object or action component.

4. Think about why that action is wanted. What results does it produce? What outcomes would it have? What effects would be created? Why are those important? What is their value?

5. Modify the verb-object component, if necessary, to emphasise results instead of activity.

6. Think about ways of measuring the work you have begun to specify.

7. Draft some measurable standards the work must satisfy. How could you tell whether or not the work or results occurred? What is the measure of those results? Quality? Quantity? Speed? Money? Frequency? Ratios of some kind?

8. Modify the action component further, if necessary.

9. Think about the time frames in which the work is to be accomplished.

10. Specify some deadlines, time frames, due dates, etc.

11. Ask the person who is to be accountable for meeting it what he (or she) thinks it means. Or, if you are writing them for yourself, ask your boss to tell you what she (or he) thinks it means.

12. Rewrite it again, if necessary.

The regular or proper day-to-day feedback provides important information that could feed into the quarterly, mid-year and end-of-year reviews; particularly when the appraiser keeps records of relevant occurrences and shares them with the appraisee on daily basis.

\section{Review And Appraisal}

This is the time of the institutional year (May/June) when supervisor (appraiser) would meet with their subordinate (s) to discuss the latter's performance for the year with the focus on targets/objectives, competencies, expectations and routine duties. Appraisal is a rating which the appraiser gives for the level of achievement on each target or competency. The rating is done at the end of the review meeting, and the rating for each target is communicated to the appraisee.

Preparation for the review meeting: Before June ending, HOD, Human Resource would send a notice to all departments, reminding them about the annual review and appraisal and urge them to ensure integrity, transparency and trust. This important activity may take place at the last week of June. In preparing:

- The school's boardroom or the HODs' offices could be used for the meeting. This is to avoid interruptions.

- Exact date, time and venue should be agreed upon by the appraiser and appraisee.

- The appraiser in preparing, should go over the targets/objectives, competencies, key duties, observations, occurrences that have been recorded and ratings that would be discussed with the appraisee.

- The things in bullet point 3 could be discussed with the boss (if the supervisor is not the boss) for a consensus.

- Any disagreements or discrepancies should be resolved before draft is presented to the appraisee for scrutiny and review. 
- The appraiser should present the appraisee with a copy of the written evaluation at least 3-5 working days before the intended date of the Appraisal.

- The appraisee should examine the appraisal, recognizing that it is a draft intended to prepare the appraisee for discussion during the appraisal meeting.

- The appraisee should also make written or mental notes of clarifications needed (if any) or questions to be asked.

- If by any reason either party cannot keep the appraisal appointment the party in default is responsible for informing the other party in advance and a new date set.

The appraisal process for administrative and other support services staff (Diagram 1):

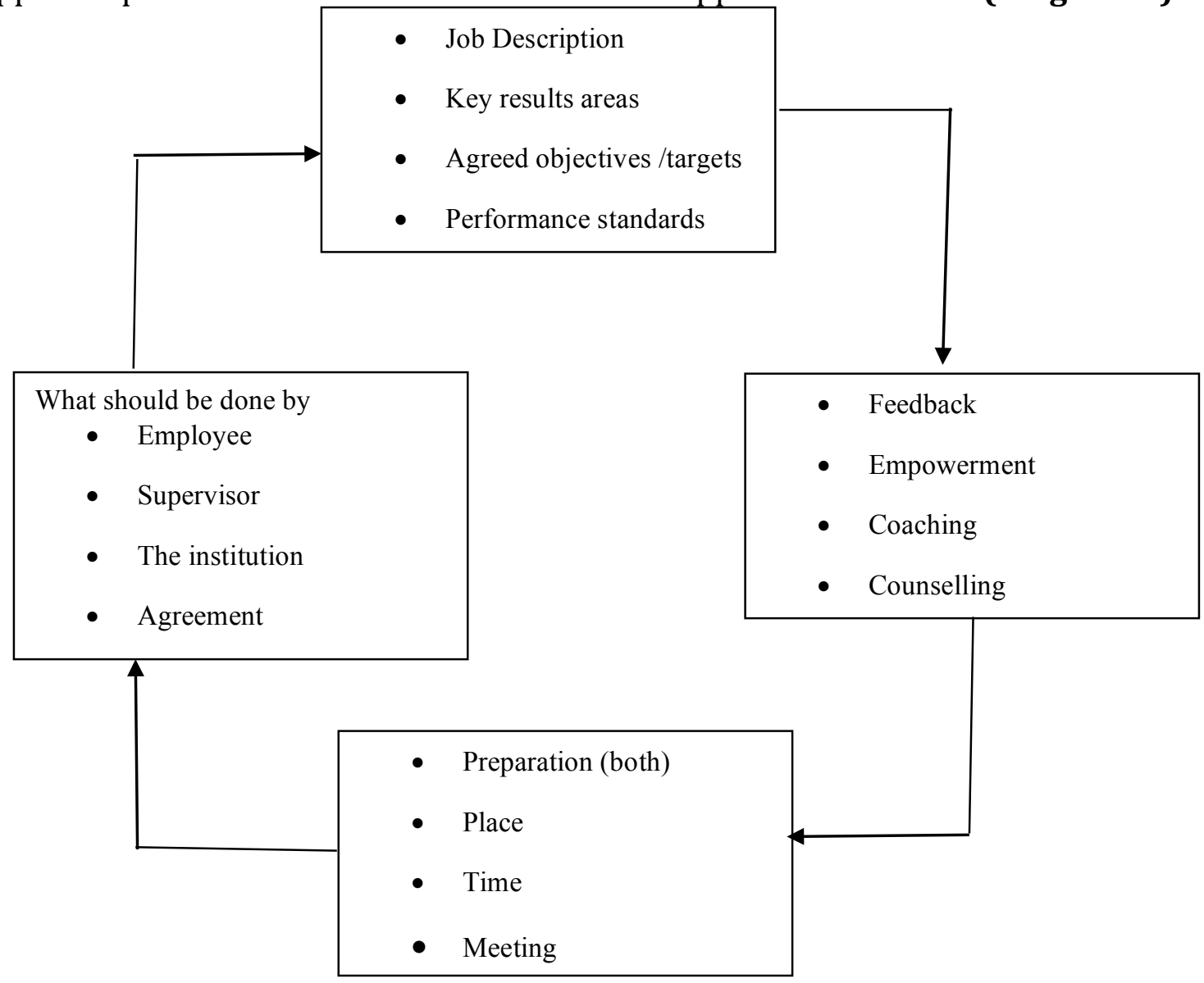

The diagram depicts performance management cycle or process. It is unending. The first (1) step shows setting targets, competencies and performance standards. Step 2 consists of informal feedback aimed at improving performance during the appraisal period. This notice should also remind appraisers to begin their preparation for appraising their employees at the end of the cycle, as at Step 3 Step 4 consists of a Performance Enhancement and Personal Development Plan emanating from Step 3 and feeding into Step 1 for the next cycle or process.

\section{Appraisal forms:}

In addition to the institution's evaluation forms, below are recommended performance objectives/standards and expectations forms for administrative and other support services staff: 


\section{Table 1:}

Performance Standards \& Expectations Form

To Be Completed And Discussed With Each Employee

At the beginning of the appraisal cycle.

(This Form May Also Be Used For Interim Appraisal)

EMPLOYEE'S NAME:

SUPERVISOR'S NAME:

REVIEW PERIOD:
POSITION:

MANAGER/HOD/EQUIVALENT:

FACULTY/DEPT/SECTION:

Example Of Non-Routine Objectives Rated Templete

Key Performance Objectives/Standards \& Expectations- (Staff member's Operational Plan)

In the space provided, specify objectives and the accompanying performance indicators

(measures) for the period under review.

Try to set A-SMARTER Objective each time that is aligned - Specific, Measurable, Attainable, Realistic, Timely, Exciting, and Recorded.

Assess actual performance by selecting a rating from the scale $\mathbf{1}, \mathbf{2}, \mathbf{3}, \mathbf{4}, \mathbf{5}$ where $\mathbf{1}$ is lowest and $\mathbf{5}$ is highest.

\begin{tabular}{|c|c|c|c|c|c|c|c|}
\hline \multirow{2}{*}{$\begin{array}{l}\text { Non-Routine Activities: } \\
\text { Set Performance } \\
\text { Objectives_- } \\
\text { (with Standards \& } \\
\text { Expectations) }\end{array}$} & \multirow{2}{*}{$\begin{array}{l}\text { Actual Performance } \\
\text { Achieved }\end{array}$} & \multicolumn{5}{|c|}{ Rating assessed } & \multirow[t]{2}{*}{ RA } \\
\hline & & 5 & 4 & 3 & 2 & 1 & \\
\hline $\begin{array}{l}\text { 1. Reduce overtime } \\
\text { from } 30 \% \text { to } 20 \% \\
\text { during the third } \\
\text { half of } 2018\end{array}$ & $\begin{array}{l}\text { Overtime increased to } \\
35 \% \text { during target } \\
\text { period. }\end{array}$ & & & & & $x$ & 1 \\
\hline $\begin{array}{l}\text { Reduce absenteeism from } \\
10 \% \text { to } 5 \% \text { during the } \\
\text { next } \\
12 \text { months }\end{array}$ & $\begin{array}{l}\text { Absenteeism reduced } \\
\text { from } 10 \text { to } \\
8 \% \text { during target } \\
\text { period }\end{array}$ & & & & $x$ & & 2 \\
\hline $\begin{array}{l}\text { Increase Equipment } \\
\text { availability from } \\
\text { present } 70 \% \text { to } 80 \% \\
\text { during the third } \\
\text { quarter of } 2018\end{array}$ & $\begin{array}{l}\text { Equipment availability } \\
\text { increased to } 85 \% \\
\text { during target period. }\end{array}$ & & & & & & 3 \\
\hline $\begin{array}{l}\text { Establish and display } \\
\text { Vision and Mission } \\
\text { Statements in reception } \\
\text { area for each of four } \\
\text { Faculties by December } \\
2018 .\end{array}$ & $\begin{array}{l}\text { Vision and Mission } \\
\text { statements } \\
\text { established and } \\
\text { displayed in all } \\
\text { Faculties during target } \\
\text { period }\end{array}$ & $x$ & & & & & 5 \\
\hline \multirow[t]{3}{*}{$\begin{array}{l}\text { Ensure that a copy of } \\
\text { Accra Technical } \\
\text { University } \\
\text { Values is posted in all } \\
\text { reception areas by } \\
\text { December } 2018\end{array}$} & $\begin{array}{l}\text { Copies of Accra } \\
\text { Technical Values } \\
\text { posted in all reception } \\
\text { areas before December } \\
2018\end{array}$ & $x$ & & & & & 5 \\
\hline & & \multicolumn{5}{|c|}{ Total score: } & 16 \\
\hline & & \multicolumn{5}{|c|}{ Average scores: } & \\
\hline
\end{tabular}


Table 2:

Performanceobjectives/Standards \& Expectations Form

To Be Completed And Discussed With Each Employee

At the beginning of the appraisal cycle.

(This Form May Also Be Used For Temporary Appraisal)

EMPLOYEE'S NAME:

SUPERVISOR'S NAME:

REVIEW PERIOD:
POSITION:

MANAGER/HOD/EQUIVALENT:

FACULTY/DEPT/SECTION:

Example Of Routine Objectives Rated Templete

\begin{abstract}
Key Performance Objectives/Standards \& Expectations- (Staff member's Operational
Plan)

In the space provided, specify objectives and the accompanying performance indicators (measures) for the period under review.

Try to set A-SMARTER Objective each time that is aligned - Specific, Measurable, Attainable,

Realistic, Timely, Exciting, and Recorded.

Assess actual performance by selecting a rating from the scale 1, 2, 3, 4, 5 where $\mathbf{1}$ is lowest and 5 is highest.
\end{abstract}

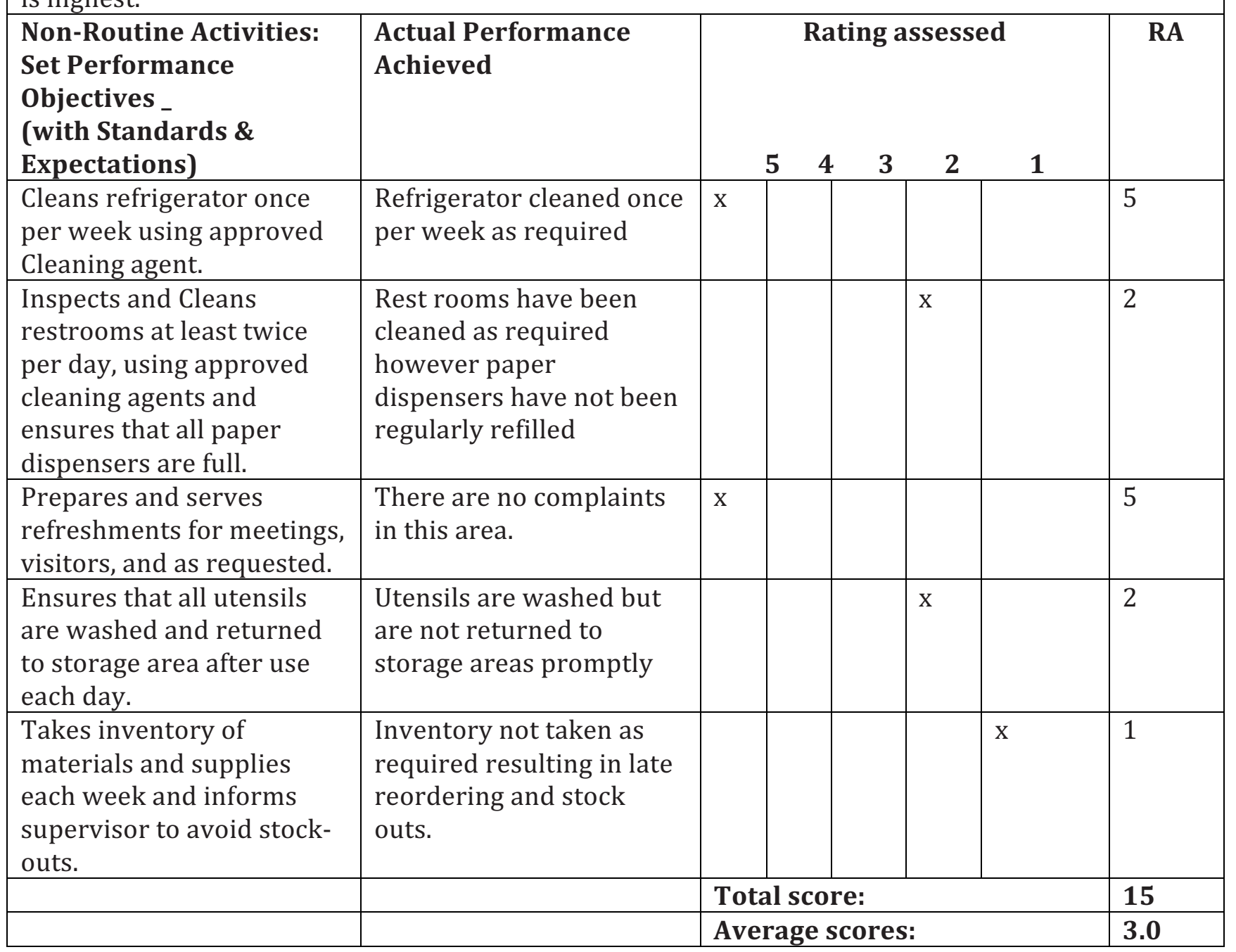

SUMMARY FINDINGS, CONCLUSIONS AND RECOMMENDATIONS

Target setting is done from the top that is, it should start from the Vice Chancellor, Pro Vice Chancellor, etc, and then it trickles down the ladder. Targets would be set from the strategic goals of the institution. For the purpose of pilot testing, the HRMD and Administration could be 
used for introduction of PMS in the institution. The HODs and their direct assistants (Assistant Registrars) would set their targets based on the job descriptions and the roles they usually play. The HODs can meet with the rest of the staff in the department to set targets based on their routine work.

The following were some observations made:

- Setting real targets would be new a concept to staff and therefore, there may be the need for training or orientation for those involved.

- PMS could be implemented if it would be discussed and accepted by the institution's Council.

- PMS would only succeed if top management (Vice Chancellor, Pro Vice Chancellor, Registrar, Financial Officer, Academic Deans etc.) think it would be the right direction for the advancement of the institution

- The introduction of the new assessment system like PMS that relates performance to appropriate rewards or sanctions may take considerable time before it acceptability.

- There would be the need for change champions to lead and sustain performance management initiatives and to build performance management culture.

- Lack of performance orientation and insufficient accountability standards may lead to failure in the implementation of PMS.

\section{Conclusion}

- Regular monitoring and evaluation of departmental and employee performance through, formal and informal feedback would allow for midcourse correction if employee performance is going off target. Monitoring how well HRMD is facilitating the Performance Management System itself would be a shared responsibility among the HRMD, HODs and other stakeholders like the unions represented on campus.

- PMS and Performance Appraisal training for users on a refresher basis would become necessary from time to time. Concept assessment and approval by Vice Chancellor, Pro Vice Chancellor and the entire management staff would be key for the success of this system. HRMD should generate reports which highlight the appraisal backlog existing in each responsibility area and remind departments to clear these by a stated time.

- It would be expected that overtime, it would become necessary to fine tune the process and adjust as the situation demands. In the meanwhile, this manual could prove helpful to ensure that the objectives of Accra Technical University's PMS are met. It is also hoped that this would increase the level of employee trust and uncertainties associated with performance appraisal.

- Ultimately, Accra Technical University would be the beneficiary of higher levels of effectiveness and efficiency as it transitions from polytechnic to a technical university since both staff and management would be working towards the achievement of set targets (with strategic goals in mind).

\section{Benefits and Recommendations:}

- All categories of staff would focus on achieving their targets thereby enhancing performance.

- Staff would be more committed to their obligations if they know that in addition to their salaries, the institution would institute performance -related incentives/ recognition.

- Training (on implementation of PMS) would be required to make performance management a reality. This is because performance management skill would have to be emphasized in the ATU.

- HODs and other Supervisors should be trained to lead the change. That is, the implementation of PMS. 
- Efforts must be made by management to aid planning, implementation, monitoring and evaluation processes. This would help in effective implementation of PMS in the entire institution.

- Although salary increments are made by government across board with reference to performance and increase level of standard of living across the country, it would be helpful to consider PMS as an auxiliary option where ATU would look for internally generated funds to give recognition to staff whose performance are exception which would lead to increase staff output.

\section{References}

Aguinis, Herman. 2013. $3^{\text {rd }}$ Edition. Performance Management. Dorling Kindersley India Pvt. Ltd.

Elaine D. Pulakos 2004. Performance Management (a roadmap for developing, implementing and evaluating performance). SHRM Foundation publication.

Gary Dessler (2011), Human Resource Management (Pearson), Twelfth edition

Kwadwo Asare-Bediako (2013), Professional skills in Human Resource Management, Third Edition.

Laurie J. Mullins (2010), Management \& Organisational Behaviour, Ninth edition.

Locke, E. A. (1968), Toward a Theory of Task Performance and Incentive, Organisational Behaviour \& Human Performance.

Locke E. A. \& Latham G.P. (1984) Goal Setting: A Motivational Technique that works, Englewoods /cliffs, N. J., Prentice-Hall

hrcouncil.ca

Swan S. W. (1991) How to Do a Superior Performance Appraisal Published by John Wiley \& Sons.

www.managementstudyguide.com (20-08-15)

www.mona.uwi.edu/hrd/forms/Performance Management Policy.pdf(Performance Management Policy Manual of University of West Indies - Retrieved on 30 April 2016) 